\title{
Associação de marcadores moleculares SNP com o conteúdo de ácido linolênico em sementes de soja
}

\author{
Marcos de Oliveira Pinto(1), Pedro Ivo Vieira Good-God(2), \\ Maurílio Alves Moreira ${ }^{(3)}$ e Everaldo Gonçalves de Barros ${ }^{(4)}$
}

\begin{abstract}
(1)Embrapa Milho e Sorgo, Rodovia MG 424, Km 65, CEP 35701-970 Sete Lagoas, MG. E-mail: marcosbqiufv@yahoo.com.br (2)Universidade Federal de Viçosa (UFV), Campus Rio Paranaíba, Rodovia MG 230, Km 7, Caixa Postal 22, CEP 38810-000 Rio Paranaíba, MG. E-mail: pedro.god@ufv.br (3)UFV, Departamento de Bioquímica e Biologia Molecular, Avenida P.H. Rolfs, s/no, CEP 36570-000 Viçosa, MG. E-mail: moreira@ufv.br ${ }^{(4)}$ UFV, Departamento de Biologia Geral, Viçosa, MG. E-mail: ebarros@ufv.br
\end{abstract}

Resumo - O objetivo deste trabalho foi validar a associação de marcadores moleculares do tipo "single nucleotide polymorphism" (SNP) para os genes FAD3A, FAD3B e FAD3C com o conteúdo de ácido linolênico (18:3) em sementes de soja e analisar a influência dos parâmetros genéticos destes marcadores nesta característica. Foram genotipadas 185 progênies $\mathrm{F}_{2}$ derivadas do cruzamento entre A29 (mutante para os três genes $F A D 3,1 \%$ de $18: 3$ ) e Tucunaré (genótipo selvagem, 11\% de 18:3). Os marcadores moleculares para os genes $F A D 3 A, F A D 3 B$ e $F A D 3 C$ explicaram a variação do conteúdo de 18:3 nas populações segregantes $\mathrm{F}_{2} \mathrm{e}$ $\mathrm{F}_{2: 3}$. Além disso, as substituições alélicas no loco $F A D 3 A$ proporcionam maiores variações no conteúdo de 18:3 que as substituições nos outros dois locos.

Termos para indexação: Glycine max, FAD3A, FAD3B, FAD3C, 18:3, substituição alélica.

\section{Association of SNP markers with the linolenic acid content in soybean seeds}

\begin{abstract}
The objective of this work was to validate the association of single nucleotide polymorphism (SNP) markers for the genes $F A D 3 A, F A D 3 B$, and $F A D 3 C$ with the linolenic acid content (18:3) in soybean seeds and to analyze the influence of the genetic parameters of these markers on this trait. One hundred and eighty-five $\mathrm{F}_{2}$ progenies derived from a cross between A29 (mutant for the three FAD3 genes, 1\% 18:3 content) and Tucunaré (wild-type genotype, 11\% 18:3 content) were genotyped. The molecular markers for genes FAD 3A, FAD3B, and $F A D 3 C$ explained the variations in 18:3 content of the $\mathrm{F}_{2}$ and $\mathrm{F}_{2: 3}$ segregating populations. In addition, allelic substitutions in the $F A D 3 A$ locus provide greater variations in 18:3 content than substitutions in the other two loci.
\end{abstract}

Index terms: Glycine max, FAD3A, FAD $3 B, F A D 3 C, 18: 3$, allelic replacement.

\section{Introdução}

As propriedades físico-químicas e biológicas do óleo são diretamente afetadas pela sua composição de ácidos graxos. A grande diversificação na utilização do óleo de soja [Glycine max (L.) Merr.] tem demandado o desenvolvimento de genótipos com composição modificada de ácidos graxos, mais adequada a cada tipo de produto. Em razão da baixa estabilidade oxidativa do ácido linolênico (18:3), há interesse no desenvolvimento de genótipos de soja que apresentem baixos teores deste ácido, principalmente para aplicações na indústria alimentícia e na produção de biodiesel (Gerde et al., 2007; Knothe, 2007; Farhoosh et al., 2009; Ramos et al., 2009; Santos et al., 2013).
A síntese de 18:3 é catalisada por $\omega$-3-dessaturases, tendo o ácido linoleico (18:2) como substrato (Baud \& Lepiniec, 2010). Três genes (FAD 3A, FAD3B e FAD3C) que codificam $\omega$-3-dessaturases afetam diretamente o acúmulo de 18:3 em sementes de soja (Bilyeu et al., 2003). Genótipos mutantes, com baixos teores de 18:3, já tiveram os alelos do gene $F A D 3 A$ bem caracterizados, o que tem permitido o desenvolvimento de marcadores moleculares do tipo "single nucleotide polymorphism" (SNP).

Bilyeu et al. (2003) caracterizaram os três genes $(F A D 3 A, \quad F A D 3 B$ e $F A D 3 C)$ responsáveis pelo conteúdo de 18:3 em sementes de soja. No gene $F A D 3 A$ da linhagem A5, foi identificada uma deleção que permite distinguir o alelo mutante dos alelos 
para conteúdo normal de 18:3. Os SNPs nos genes $F A D 3 B$ e $F A D 3 C$ de A29 foram posteriormente caracterizados por Bilyeu et al. (2006), o que permitiu o desenvolvimento de marcadores moleculares do tipo PCR-RFLP específicos para os alelos de A29. O acesso PI 361088B (3,8\% de 18:3) apresenta inserção de dois resíduos de timina na posição 310 do gene $F A D 3 A$, o que muda o quadro de leitura e faz com que surja um códon de parada prematuro na posição 328. A mutação no genótipo M5 (3,3\% de 18:3) é similar à de PI 3661088B, também com uma mudança no quadro de leitura; no entanto, neste caso, ocorre a deleção de 19 nucleotídeos na posição 1057, o que resulta em uma proteína com 25 resíduos de aminoácidos a mais na extremidade C-terminal. O genótipo CX1512-44 (3\% de 18:3) apresenta uma mutação de apenas um par de nucleotídeos na posição 811, exatamente no sítio de recomposição eucariótica ("splicing"), o que leva à formação de uma proteína com estrutura alterada. O genótipo C1640 (3,7\% de 18:3) também apresenta mutação com troca de bases, mas esta se encontra em região codificadora: o códon para triptofano (TGG) no éxon 6 é modificado para um códon de parada (TGA) (Chappell \& Bilyeu, 2007).

Com base em sequências genômicas do genótipo A29 (1\% de 18:3), foi possível o desenvolvimento de marcadores moleculares do tipo SNP para alelos dos genes FAD3A, FAD3B e FAD3C (Bilyeu et al., 2006). A utilização de marcadores moleculares associados a esses genes é promissora para a seleção de genótipos superiores com reduzidos teores de 18:3 (Bilyeu et al., 2005, 2006, 2011; Reinprecht et al., 2009).

Um dos principais objetivos em programas de melhoramento da qualidade de sementes de soja é aumentar a estabilidade oxidativa do óleo, principalmente pela redução do conteúdo de 18:3 (Wilson, 2004; Mahmoud et al., 2006; Fehr, 2007). A composição final de ácidos graxos é influenciada pelo ambiente, por fatores genéticos e pela interação entre ambos. Vários fatores têm sido citados como indutores de alterações no processo de biossíntese de lipídeos, entre os quais se destaca a temperatura de cultivo durante o enchimento das sementes. $\mathrm{O}$ aumento da temperatura de cultivo da soja normalmente provoca aumento no conteúdo de 18:1 e redução nos conteúdos de 18:2 e 18:3 (Oliva et al., 2006; Bachlava \& Cardinal, 2009). Dessa forma, em razão do pronunciado efeito ambiental, a utilização de marcadores moleculares pode acelerar o processo de obtenção de genótipos superiores, com reduzidos teores de 18:3 (Xu \& Crouch, 2008).

O conteúdo de 18:3, além de ser influenciado pelo ambiente, também pode ser determinado pelo "background" genético. Portanto, para a utilização de marcadores SNP na seleção assistida por marcadores, com vistas à redução de 18:3, é fundamental verificar a associação dos SNPs já relatados (Bilyeu et al., 2006) nas populações segregantes obtidas a partir de genótipos elites adaptados às condições de cultivo do Brasil.

O objetivo deste trabalho foi validar a associação de marcadores moleculares do tipo SNP para os genes $F A D 3 A, F A D 3 B$ e $F A D 3 C$ com o conteúdo de ácido linolênico (18:3) em sementes de soja e analisar a influência dos parâmetros genéticos destes marcadores nesta característica.

\section{Material e Métodos}

Foram utilizados os genótipos A29 e Tucunaré, além das populações segregantes derivadas de seu cruzamento. A cultivar Tucunaré, desenvolvida pela Fundação Mato Grosso, é amplamente cultivada no Brasil Central e apresenta elevado conteúdo de óleo, com aproximadamente $11 \%$ de 18:3. Já o genótipo A29, desenvolvido por pesquisadores da Universidade Estadual de Iowa, EUA, apresenta apenas 1\% de 18:3 e foi utilizado como fonte doadora de genes para baixos teores desse ácido. O genótipo A29 foi obtido pela combinação de três mutações independentes: fan da linhagem A5, fan2 da linhagem A23 e fan3 da linhagem A89-144003 (Bilyeu et al., 2006).

Para a obtenção das populações segregantes, inicialmente foram efetuados cruzamentos entre A29 x 'Tucunaré'. O híbrido $F_{1}$ foi autofecundado, tendose obtido 185 progênies $F_{2}$; esse material foi novamente autofecundado para obtenção da população $\mathrm{F}_{2: 3}$.

A extração dos ácidos graxos das sementes de soja e sua derivatização a metil-ésteres de ácidos graxos foram realizadas seguindo metodologia descrita por Jham et al. (1982). Foram determinados os conteúdos dos ácidos graxos nas variedades A29 e Tucunaré, bem como nos indivíduos das populações segregantes nas gerações $\mathrm{F}_{2}$ e $\mathrm{F}_{2: 3}$.

O DNA de folha dos parentais e dos 185 indivíduos da população $F_{2}$ foi extraído (Doyle \& Doyle, 1990), e 
a genotipagem foi realizada seguindo os procedimentos descritos por Bilyeu et al. (2005).

Os iniciadores utilizados para a amplificação de segmentos dos genes foram: FAD3A Forward 5' TTGCATCACCATGGTCATCAT 3'; FAD 3 A Reverse 5' AGCTATTATCTAGCATTAACCTCA 3'; $F A D 3 B$ Forward 5' AGCCACAGAACTCACCATCAA 3',FAD3BReverse 5'TGGCACAGTGAATCTAATG3'; FAD 3C Forward 5'TTGGATCAACAACATTCACCA3' e FAD3C Reverse 5' CATCACATGTTTGTGGTCTTGA $3^{\prime}$. As reações de PCR foram conduzidas com 30 ciclos, constituídos da seguinte sequência: $30 \mathrm{~s} \mathrm{a} 94^{\circ} \mathrm{C}, 30 \mathrm{~s} \mathrm{a}$ $55^{\circ} \mathrm{C}$ e $30 \mathrm{~s}$ a $72^{\circ} \mathrm{C}$. Após os 30 ciclos, realizou-se uma etapa de extensão final de 7 min a $72^{\circ} \mathrm{C}$, e, finalmente, a temperatura foi reduzida a $4^{\circ} \mathrm{C}$. Os produtos da amplificação contidos em $10 \mu \mathrm{L}$ de cada reação, para os genes $F A D 3 B$ e $F A D 3 C$, foram clivados com enzimas de restrição, para evidenciar o polimorfismo do SNP. Para o gene $F A D 3 B$, foi utilizada a enzima $H p a \mathrm{I}$ (2,5 U) e, para o gene FAD3C, a enzima BccI (5 U).

Os fragmentos amplificados foram separados por eletroforese em gel não desnaturante de poliacrilamida, a $10 \%$, durante 4 horas, a $120 \mathrm{~V}$. Para a obtenção das imagens, os géis foram corados em solução de brometo de etídio $\left(0,2 \mathrm{mg} \mathrm{mL}^{-1}\right)$, visualizados sob luz ultravioleta e fotografados com o sistema de fotodocumentação Eagle Eye II (Stratagene, La Jolla, CA, EUA).

As análises estatísticas quanto ao teor de ácidos graxos foram realizadas com o programa Genes (Cruz, 2006). Para analisar a associação dos marcadores com os teores de ácidos graxos, utilizou-se a análise de regressão linear. Para o marcador FAD3A, de natureza dominante, foi utilizado o modelo $Y_{j}=\beta_{o}+\beta_{1} X_{\mathrm{lj}}+\varepsilon_{j}$, em que: $Y_{j}$ é o valor da característica avaliada no j-ésimo indivíduo; $X_{\mathrm{lj}}$ é o código do marcador para o j-ésimo indivíduo; $\beta_{\mathrm{o}}$ é o intercepto da regressão (média da característica); $\beta_{1}$ é a inclinação da reta; e $\varepsilon_{\mathrm{j}}$ é o erro aleatório. Para os marcadores $F A D 3 B$ e $F A D 3 C$, de natureza codominante, foi utilizado o modelo $Y_{j}=\beta_{o}+\beta_{1} X_{1 j}+\beta_{2} X_{2 j}+\varepsilon_{j}$, em que: $\beta_{1}$ é a inclinação da reta para o efeito aditivo; $\beta_{2}$ é a inclinação da reta para o efeito dominante; e $\varepsilon_{\mathrm{j}}$ é o erro aleatório. Foi utilizado o programa GQMOL (Cruz \& Schuster, 2012) para análise de associação dos marcadores com as características. $\mathrm{O}$ efeito da substituição alélica foi avaliado pelo teste $t$, a partir das diferenças nas médias do conteúdo de 18:3, tendose considerado a modificação dos alelos em um gene alvo e a manutenção dos alelos dos outros dois genes.
Utilizou-se a análise de regressão linear múltipla para avaliar os efeitos aditivos e não aditivos, relativos aos marcadores FAD $3 B$ e FAD $3 C$ avaliados conjuntamente, sobre o conteúdo de ácido linolênico nas gerações $\mathrm{F}_{2} \mathrm{e}$ $\mathrm{F}_{2: 3}$. Os efeitos lineares e quadráticos, bem como suas interações, permitiram avaliar a ação gênica aditiva dominante e os diferentes tipos de epistasia. Como o marcador $F A D 3 A$ é de natureza dominante, a análise de regressão foi realizada primeiro para o conjunto de indivíduos A_e, posteriormente, para o conjunto de indivíduos aa, a fim de remover os efeitos do marcador FAD3A.

\section{Resultados e Discussão}

O genótipo A29 apresentou baixíssimo conteúdo de $18: 3$, próximo a $1 \%$ (Tabela 1 ), o que corrobora os resultados obtidos por Bilyeu et al. (2005). Nas populações $F_{2}$ e $F_{2: 3}$, verificou-se ampla variação no conteúdo dos cinco principais ácidos graxos encontrados no óleo de soja. Merece destaque a amplitude observada no conteúdo de 18:3: de 0,97 a $7,95 \%$ na população $\mathrm{F}_{2}$; e de 1,23 a $11,94 \%$ na população $\mathrm{F}_{2: 3}$. Bilyeu et al. (2006) relataram que o genótipo

Tabela 1. Média, desvio-padrão, e valores mínimos e máximos dos teores dos ácidos palmítico (16:0), esteárico (18:0), oleico (18:1), linoleico (18:2) e linolênico (18:3) dos genótipos A29 e Tucunaré, e das populações segregantes $F_{2}$ e $\mathrm{F}_{2: 3}$ resultantes de seu cruzamento.

\begin{tabular}{lccccc}
\hline Parâmetro & \multicolumn{5}{c}{ Ácido graxo } \\
\cline { 2 - 6 } & $16: 0$ & $18: 0$ & $18: 1$ & $18: 2$ & $18: 3$ \\
\hline \multirow{5}{*}{ Média } & 11,01 & 4,07 & 21,72 & 62,03 & 1,19 \\
Desvio-padrão & 0,47 & 0,45 & 3,22 & 3,41 & 0,18 \\
Mínimo & 9,66 & 3,05 & 15,22 & 54,67 & 0,90 \\
Máximo & 11,88 & 5,11 & 28,33 & 69,85 & 1,85 \\
\hline \multirow{5}{*}{ Média } & 11,41 & 3,11 & 19,14 & 58,18 & 8,00 \\
Desvio-padrão & 0,36 & 0,26 & 1,19 & 0,82 & 0,73 \\
Mínimo & 10,91 & 2,71 & 17,08 & 56,57 & 6,00 \\
Máximo & 12,17 & 3,67 & 21,96 & 59,36 & 9,07 \\
\hline & \multicolumn{5}{c}{ População $\mathrm{F}_{2}$} \\
Média & 10,29 & 3,62 & 24,87 & 57,24 & 3,95 \\
Desvio-padrão & 1,52 & 1,29 & 4,46 & 3,95 & 1,39 \\
Mínimo & 0,67 & 2,27 & 9,66 & 37,06 & 0,97 \\
Máximo & 14,23 & 19,97 & 47,89 & 65,92 & 7,96 \\
\hline & 11,11 & 3,98 & 17,53 & 61,76 & 5,61 \\
Média & 0,57 & 0,58 & 1,70 & 2,75 & 2,42 \\
Desvio-padrão & 9,65 & 2,40 & 14,14 & 55,17 & 1,24 \\
Mínimo & 12,67 & 5,59 & 27,82 & 68,01 & 11,95 \\
Máximo & \multicolumn{5}{c}{ População $\mathrm{F}_{2: 3}$} \\
\hline
\end{tabular}

Pesq. agropec. bras., Brasília, v.48, n.3, p.263-269, mar. 2013 DOI: 10.1590/S0100-204X2013000300004 
IA3017 apresenta as mesmas mutações para os genes $F A D 3 A, F A D 3 B$ e $F A D 3 C$ que o genótipo A29, além de apresentar conteúdo de 18:3 de aproximadamente $1 \%$. Segundo estes autores, o conteúdo de 18:3 determinado na população segregante $\mathrm{RC}_{1} \mathrm{~F}_{2}$ derivada do retrocruzamento com o genótipo SS97-6946 (8\% de 18:3) apresentou variação de 10 a $1 \%$, amplitude similar à encontrada no presente trabalho.

As correlações fenotípicas entre o conteúdodosácidos graxos apresentaram valores divergentes (Tabela 2), quando comparados os resultados entre as gerações $F_{2}$ e $\mathrm{F}_{2: 3}$. Entretanto, o sentido e a significância de algumas correlações se mantiveram. A correlação negativa entre 18:3 e 18:1 ( $r=-0,2367)$, detectada na geração $F_{2}$,

Tabela 2. Correlações fenotípicas entre os teores dos ácidos palmítico (16:0), esteárico (18:0), oleico (18:1), linoleico (18:2) e linolênico (18:3) nas populações segregantes $F_{2}$ (diagonal superior) e $\mathrm{F}_{2: 3}$ (diagonal inferior) do cruzamento entre A29 x 'Tucunaré'.

\begin{tabular}{lccccc}
\hline Ácido graxo & $16: 0$ & $18: 0$ & $18: 1$ & $18: 2$ & $18: 3$ \\
\hline $16: 0$ & - & $-0,1746^{*}$ & $-0,1659^{*}$ & $-0,1417^{\text {ns }}$ & $0,0030^{\text {ns }}$ \\
$18: 0$ & $-0,0768^{\text {ns }}$ & - & $-0,3648^{* *}$ & $0,1621^{*}$ & $-0,0299^{\text {ns }}$ \\
$18: 1$ & $-0,1455^{*}$ & $-0,5429^{* *}$ & - & $-0,8613^{* *}$ & $-0,2367^{* *}$ \\
$18: 2$ & $-0,1081^{\text {ns }}$ & $-0,0516^{\text {ns }}$ & $-0,3562^{* *}$ & - & $-0,0760$ \\
$18: 3$ & $0,0090^{\text {ns }}$ & $0,2179^{* *}$ & $-0,1341^{\text {ns }}$ & $-0,8465^{* *}$ & - \\
\hline
\end{tabular}

ns Não significativo. * e **Significativo a 5 e $1 \%$ de probabilidade, respectivamente. não se manteve significativa em $\mathrm{F}_{2: 3}$. Nesta geração, o conteúdo de 18:3 correlacionou-se positivamente com o de 18:0 (r=0,2179) e negativamente com o de 18:2 $(\mathrm{r}=-0,8465)$. Neste último caso, destacase a elevada magnitude de correlação observada. O conteúdo de 18:3 comumente se correlaciona com os de 18:1 e 18:2 (Fehr, 2007). No entanto, a correlação entre ácidos graxos em sementes de soja é fortemente influenciada por componentes ambientais (Carrera et al., 2011), o que está de acordo com as variações obtidas para as estimativas das correlações fenotípicas.

$\mathrm{Na}$ análise de regressão linear, constatou-se que, para a geração $F_{2}$, apenas o conteúdo de 18:3 é significativamente influenciado pelos genes $F A D 3 A$, $F A D 3 B$ e $F A D 3 C$ (Tabela 3). O marcador FAD $3 A$ explicou $21,92 \%$ da variação do conteúdo de $18: 3$, enquanto os marcadores $F A D 3 B$ e $F A D 3 C$ explicaram 4,01 e 11,90\%, respectivamente. Foi observado efeito genético aditivo predominante para os marcadores relativos aos genes $F A D 3 B$ e $F A D 3 C$, sem que se detectasse qualquer efeito relacionado aos desvios causados pela dominância.

$\mathrm{Na}$ geração $\mathrm{F}_{2: 3}$, verificou-se que os conteúdos de 18:2 e 18:3 foram significativamente influenciados pelos três genes FAD3 (Tabela 3). O marcador FAD3A explicou $21,87 \%$ da variação no conteúdo de $18: 2$ e $30,33 \%$ da variação no conteúdo de 18:3. Os marcadores $F A D 3 B$ e FAD3C explicaram, respectivamente, 5,74 e 9,04\% da

Tabela 3. Parâmetros da análise de regressão para os marcadores dos genes FAD3A, FAD3B e FAD3C, quanto aos teores dos ácidos palmítico (16:0), esteárico (18:0), oleico (18:1), linoleico (18:2) e linolênico (18:3) nas populações $\mathrm{F}_{2}$ e $\mathrm{F}_{2: 3}$, derivadas do cruzamento entre A29 x 'Tucunaré'.

\begin{tabular}{|c|c|c|c|c|c|c|c|c|c|c|c|c|c|c|c|}
\hline \multirow{2}{*}{$\begin{array}{l}\text { Ácido } \\
\text { graxo }\end{array}$} & \multirow[t]{2}{*}{ Marcador } & \multicolumn{7}{|c|}{ População $F_{2}$} & \multicolumn{7}{|c|}{ População $\mathrm{F}_{2: 3}$} \\
\hline & & Teste F & $\beta_{0}$ & $\beta_{1}$ & Teste $\mathrm{t}$ & $\beta_{2}$ & Teste $\mathrm{t}$ & $\mathrm{R}^{2}$ & Teste $\mathrm{F}$ & $\beta_{0}$ & $\beta_{1}$ & Teste $\mathrm{t}$ & $\beta_{2}$ & Teste $\mathrm{t}$ & $\mathrm{R}^{2}$ \\
\hline \multirow{3}{*}{$16: 0$} & FAD3A & $1,00^{\mathrm{ns}}$ & 10,29 & $-0,03$ & $0,87^{\mathrm{ns}}$ & - & - & 0,01 & $1,00^{\mathrm{ns}}$ & 11,11 & $-0,03$ & $0,6743^{\text {ns }}$ & - & - & 0,10 \\
\hline & $F A D 3 B$ & $0,17^{\mathrm{ns}}$ & 10,43 & 0,27 & $0,10^{\text {ns }}$ & $-0,24$ & $0,28^{\mathrm{ns}}$ & 1,96 & $1,00^{\mathrm{ns}}$ & 11,14 & 0,08 & $0,19^{\text {ns }}$ & $-0,044$ & $0,61^{\mathrm{ns}}$ & 1,03 \\
\hline & $F A D 3 C$ & $1,00^{\mathrm{ns}}$ & 10,37 & 0,03 & $0,83^{\text {ns }}$ & $-0,17$ & $0,55^{\text {ns }}$ & 0,37 & $0,17^{\mathrm{ns}}$ & 11,16 & $-0,11$ & $0,064^{\text {ns }}$ & $-0,069$ & $0,59^{\text {ns }}$ & 2,02 \\
\hline \multirow{3}{*}{ 18:0 } & FAD3A & $1,00^{\text {ns }}$ & 3,62 & 0,00 & $0,99^{\text {ns }}$ & - & - & 0,00 & $0,00 * *$ & 3,00 & 0,27 & $0,0001^{* *}$ & - & - & 8,02 \\
\hline & $F A D 3 B$ & $1,00^{\mathrm{ns}}$ & 3,54 & $-0,09$ & $0,54^{\mathrm{ns}}$ & 0,15 & $0,54^{\mathrm{ns}}$ & 0,49 & $0,20^{\text {ns }}$ & 3,96 & $-0,11$ & $0,073^{\text {ns }}$ & 0,038 & $0,66^{\mathrm{ns}}$ & 1,764 \\
\hline & $F A D 3 C$ & $0,14^{\mathrm{ns}}$ & 3,68 & 0,23 & $0,08^{\text {ns }}$ & $-0,15$ & $0,57^{\mathrm{ns}}$ & 2,13 & $1,00^{\mathrm{ns}}$ & 3,99 & $-0,06$ & $0,635^{\text {ns }}$ & $-0,001$ & $0,98^{\mathrm{ns}}$ & 0,46 \\
\hline \multirow{3}{*}{$18: 1$} & $F A D 3 A$ & $1,00^{\text {ns }}$ & 24,86 & $-0,12$ & $0,82^{\mathrm{ns}}$ & - & - & 0,03 & $0,12^{\mathrm{ns}}$ & 17,51 & $-0,32$ & $0,1148^{\text {ns }}$ & - & - & 1,32 \\
\hline & $F A D 3 B$ & $1,00^{\mathrm{ns}}$ & 24,58 & $-0,13$ & $0,78^{\text {ns }}$ & 0,52 & $0,56^{\mathrm{ns}}$ & 0,36 & $1,00^{\mathrm{ns}}$ & 17,58 & $-0,02$ & $0,91^{\mathrm{ns}}$ & $-0,103$ & $0,69^{\text {ns }}$ & 0,10 \\
\hline & $F A D 3 C$ & $1,00^{\text {ns }}$ & 24,73 & $-0,26$ & $0,59^{\mathrm{ns}}$ & 0,33 & $0,63^{\mathrm{ns}}$ & 0,33 & $0,02 *$ & 17,47 & 0,49 & $0,006^{* *}$ & 0,100 & $0,69^{\text {ns }}$ & 4,10 \\
\hline \multirow{3}{*}{$18: 2$} & FAD $3 A$ & $0,05^{\text {ns }}$ & 57,21 & $-0,92$ & $0,05^{\mathrm{ns}}$ & - & - & 2,01 & $0,00 * *$ & 61,66 & $-2,13$ & $0,0 * *$ & - & - & 21,87 \\
\hline & $F A D 3 B$ & $1,00^{\mathrm{ns}}$ & 57,39 & 0,34 & $0,56^{\mathrm{ns}}$ & $-0,21$ & $0,72^{\mathrm{ns}}$ & 0,39 & $0,01 * *$ & 61,69 & 0,95 & $0,002 * *$ & 0,215 & $0,60^{\text {ns }}$ & 5,74 \\
\hline & $F A D 3 C$ & $0,27^{\mathrm{ns}}$ & 57,25 & 0,65 & $0,11^{\mathrm{ns}}$ & $-0,10$ & $0,86^{\mathrm{ns}}$ & 1,43 & $0,00 * *$ & 61,68 & 1,16 & $0,0^{* *}$ & $-0,023$ & $0,95^{\mathrm{ns}}$ & 9,04 \\
\hline \multirow{3}{*}{$18: 3$} & FAD3A & $0,00 * *$ & 4,01 & 1,08 & $0,00 * *$ & - & - & 21,92 & $0,00 * *$ & 5,72 & 2,21 & $0,00 * *$ & - & - & 30,33 \\
\hline & $F A D 3 B$ & $0,02 *$ & 4,04 & $-0,38$ & $0,01^{*}$ & $-0,19$ & $0,65^{\mathrm{ns}}$ & 4,01 & $0,00 * *$ & 5,63 & $-0,89$ & $0,00 * *$ & $-0,110$ & $0,76^{\mathrm{ns}}$ & 6,39 \\
\hline & $F A D 3 C$ & $0,00^{* *}$ & 3,97 & $-0,70$ & $0,00 * *$ & 0,08 & $0,70^{\mathrm{ns}}$ & 11,90 & $0,00 * *$ & 5,74 & $-1,49$ & $0,00 * *$ & $-0,010$ & $0,98^{\text {ns }}$ & 18,96 \\
\hline
\end{tabular}

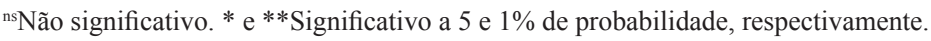


variação no conteúdo de 18:2, e 6,39 e 18,96\% da variação no conteúdo de 18:3. Novamente, o efeito genético aditivo predominante foi detectado para os marcadores relativos aos genes $F A D 3 B$ e $F A D 3 C$.

Segundo Cardinal et al. (2011), marcadores moleculares para os alelos do gene FAD $3 A$ do genótipo PI 123440 permitem explicar mais de $77,5 \%$ da variação no conteúdo de 18:3 em populações segregantes. Portanto, pode-se confirmar forte influência do produto do gene FAD3A na biossíntese desse ácido graxo.

Cruzamentos que envolvem linhagens mutantes com teores modificados de ácidos graxos evidenciam herança simples para esta característica, possivelmente pela ação de genes de efeito maior (Primomo et al., 2002; Anai et al., 2005). Entretanto, estudos mais recentes têm mostrado que a herança dos conteúdos de ácidos graxos é de natureza quantitativa (Bachlava et al., 2009; Xie et al., 2012; Wang et al., 2012).

As diferenças médias no conteúdo de 18:3, em consequência das substituições alélicas nos genes FAD $3 A$, $F A D 3 B$ e $F A D 3 C$, avaliadas na população $\mathrm{F}_{2} / \mathrm{F}_{2: 3}$ derivada do cruzamento entre A29 x 'Tucunaré', são apresentadas nas Tabelas 4, 5 e 6 . As substituições gênicas dos alelos em FAD3A proporcionam maiores variações no conteúdo de 18:3 que as substituições alélicas nos demais locos. O gene FAD3B é o que aparentemente leva à menor variação no conteúdo de 18:3, quando suas formas alélicas são alteradas.
A ação gênica aditiva foi predominante nos marcadores FAD3B e FAD3C, quando seu efeito conjunto no teor de 18:3 foi analisado por meio da regressão linear múltipla (Tabela 7). A ação gênica relativa à dominância somente foi detectada para $\mathrm{o}$ marcador $F A D 3 C$, em uma única situação. Não foi observada ação gênica epistática para o conteúdo do ácido linolênico. A análise de regressão linear múltipla confirmou os resultados da regressão linear simples, em que a ação gênica aditiva foi predominante. Ao utilizar a informação conjunta dos marcadores $F A D 3 B$ e $F A D 3 C$, foi possível explicar um percentual maior da

Tabela 4. Diferença média ${ }^{(1)}$ no conteúdo de 18:3, em consequência da substituição alélica do gene FAD3A avaliada na população derivada do cruzamento entre A29 x 'Tucunaré', em $\mathrm{F}_{2} / \mathrm{F}_{2: 3}{ }^{(2)}$.

\begin{tabular}{|c|c|c|c|}
\hline \multirow[t]{2}{*}{ Genótipo } & $\mathrm{CC}$ & $\mathrm{Cc}$ & $\mathrm{cc}$ \\
\hline & $A_{-} \rightarrow a a$ & $A_{-} \rightarrow \mathrm{aa}$ & $A_{-} \rightarrow \mathrm{aa}$ \\
\hline$\overline{\mathrm{BB}}$ & $2,41 * / 4,03 * *$ & $1,48 * / 3,43 * *$ & $1,30 * * / 3,58 * *$ \\
\hline $\mathrm{Bb}$ & $0,95^{\mathrm{ns}} / 3,71^{* *}$ & $1,44 * * / 3,29 * *$ & $1,68 * * / 4,22 * *$ \\
\hline $\mathrm{bb}$ & $2,00 * * / 3,80 * *$ & $1,99 * * / 2,68 *$ & $2,18 * * / 3,41 * *$ \\
\hline
\end{tabular}

${ }^{(1)}$ Obtida a partir da subtração do valor médio do conteúdo de 18:3 dos indivíduos com os alelos do gene $F A D 3 A$, antes da seta, pelo valor médio dos indivíduos com os alelos após a seta. Os genes $F A D 3 B$ e $F A D 3 C$ foram considerados fixos. ${ }^{(2)}$ Letras minúsculas, na representação dos genótipos, representam alelos mutantes de 'A29' para os genes $F A D 3 A$ (A), FAD3B (B)

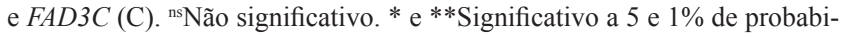
lidade, respectivamente.

Tabela 5. Diferença média ${ }^{(1)}$ no conteúdo de ácido linolênico, em consequência da substituição alélica do gene $F A D 3 B$ avaliada na população derivada do cruzamento entre $\mathrm{A} 29 \mathrm{x}$ 'Tucunaré', $\mathrm{em}_{\mathrm{F}} / \mathrm{F}_{2: 3}{ }^{(2)}$.

\begin{tabular}{|c|c|c|c|c|c|c|c|c|c|}
\hline \multirow[t]{2}{*}{ Genótipo } & \multicolumn{3}{|c|}{$\mathrm{CC}$} & \multicolumn{3}{|c|}{$\mathrm{Cc}$} & \multicolumn{3}{|c|}{$\mathrm{cc}$} \\
\hline & $\mathrm{BB} \rightarrow \mathrm{bb}$ & $\mathrm{BB} \rightarrow \mathrm{Bb}$ & $\mathrm{Bb} \rightarrow \mathrm{bb}$ & $\mathrm{BB} \rightarrow \mathrm{bb}$ & $\mathrm{BB} \rightarrow \mathrm{Bb}$ & $\mathrm{Bb} \rightarrow \mathrm{bb}$ & $\mathrm{BB} \rightarrow \mathrm{bb}$ & $\mathrm{BB} \rightarrow \mathrm{Bb}$ & $\mathrm{Bb} \rightarrow \mathrm{bb}$ \\
\hline A & $1,46 * / 2,02 *$ & $1,36^{* *} / 1,24^{\mathrm{ns}}$ & $0,10^{\mathrm{ns}} / 0,79^{\mathrm{ns}}$ & $1,00 * / 1,51^{\mathrm{ns}}$ & $0,57^{\mathrm{ns}} / 0,90^{\mathrm{ns}}$ & $0,42^{\mathrm{ns}} / 0,62^{\mathrm{ns}}$ & $0,55^{\mathrm{ns}} / 1,65^{*}$ & $-0,03^{\mathrm{ns}} /-0,17^{\mathrm{ns}}$ & $0,58^{\mathrm{ns}} / 1,82^{*}$ \\
\hline aa & $1,05 * / 1,79 *$ & $-0,10^{\mathrm{ns}} / 0,91^{\mathrm{ns}}$ & $1,15^{\mathrm{ns}} / 0,88^{\mathrm{ns}}$ & $1,51^{* *} / 0,77^{\mathrm{ns}}$ & $0,53^{\mathrm{ns}} / 0,77^{*}$ & $0,98 * * / 0,01^{\mathrm{ns}}$ & $1,43 * * / 1,48 * *$ & $0,34^{\mathrm{ns}} / 0,47^{\mathrm{ns}}$ & $1,08 * / 1,01 * *$ \\
\hline
\end{tabular}

${ }^{(1)}$ Obtida a partir da subtração do valor médio do conteúdo de 18:3 dos indivíduos com os alelos do gene $F A D 3 B$, antes da seta, pelo valor médio dos indivíduos com os alelos após a seta. Os genes $F A D 3 A$ e $F A D 3 C$ foram considerados fixos. ${ }^{(2)}$ Letras maiúsculas representam os alelos "wild type" de 'Tucunaré', e letras minúsculas representam os alelos mutantes de 'A29' para os genes $F A D 3 A(\mathrm{~A}), F A D 3 B(\mathrm{~B})$ e $F A D 3 C$ (C). ns Não significativo. * e **Significativo a 5 e $1 \%$ de probabilidade, respectivamente.

Tabela 6. Diferença média ${ }^{(1)}$ no conteúdo de ácido linolênico, em consequência da substituição alélica do gene $F A D 3 C$ avaliada na população derivada do cruzamento entre A29 x 'Tucunaré', em $\mathrm{F}_{2} / \mathrm{F}_{2: 3}{ }^{(2)}$.

\begin{tabular}{|c|c|c|c|c|c|c|c|c|c|}
\hline \multirow[t]{2}{*}{ Genótipo } & \multicolumn{3}{|c|}{$\mathrm{BB}$} & \multicolumn{3}{|c|}{$\mathrm{Bb}$} & \multicolumn{3}{|c|}{$\mathrm{bb}$} \\
\hline & $\mathrm{CC} \rightarrow \mathrm{cc}$ & $\mathrm{CC} \rightarrow \mathrm{Cc}$ & $\mathrm{Cc} \rightarrow \mathrm{cc}$ & $\mathrm{CC} \rightarrow \mathrm{cc}$ & $\mathrm{CC} \rightarrow \mathrm{Cc}$ & $\mathrm{Cc} \rightarrow \mathrm{cc}$ & $\mathrm{CC} \rightarrow \mathrm{cc}$ & $\mathrm{CC} \rightarrow \mathrm{Cc}$ & $\mathrm{Cc} \rightarrow \mathrm{cc}$ \\
\hline $\mathrm{A}$ & $2,56 * * / 2,85 * *$ & $1,39 * / 1,99 *$ & $1,18^{* *} / 0,86^{\mathrm{ns}}$ & $1,17 * * / 1,44 *$ & $0,60 * / 1,66 * *$ & $0,57 * /-0,21^{\mathrm{ns}}$ & $1,65 * * / 2,48 *$ & $0,92 * / 1,49^{\mathrm{ns}}$ & $0,73^{\text {ns }} / 0,99^{\text {ns }}$ \\
\hline aa & $1,46^{* * / 2}, 39 *$ & $0,46^{\mathrm{ns}} / 1,39^{*}$ & $1,00^{\mathrm{ns} /} 1,01^{*}$ & $1,90 * / 1,95 * *$ & $1,09^{\mathrm{ns}} / 1,24 * *$ & $0,81^{\mathrm{ns}} / 0,72^{* *}$ & $1,83 * * / 2,09 * *$ & $0,92 * / 0,37^{\mathrm{ns}}$ & $0,92^{* *} / 1,72^{\mathrm{ns}}$ \\
\hline
\end{tabular}

${ }^{(1)}$ Obtida a partir da subtração do valor médio do conteúdo de 18:3 dos indivíduos com os alelos do gene $F A D 3 C$, antes da seta, pelo valor médio dos indivíduos com os alelos após a seta. Os genes $F A D 3 A$ e $F A D 3 B$ foram considerados fixos. (2)Letras maiúsculas representam os alelos "wild type" de 'Tucunaré', e letras minúsculas representam os alelos mutantes de 'A29' para os genes $F A D 3 A(\mathrm{~A}), F A D 3 B(\mathrm{~B})$ e $F A D 3 C$ (C). ns Não significativo. * e **Significativo a 5 e $1 \%$ de probabilidade, respectivamente. 
variação do conteúdo de 18:3, com valores superiores a $20 \%$, se comparado à regressão linear simples. $\mathrm{A}$ inclusão do marcador FAD $3 A$ certamente aumentou o percentual de variação explicada no conteúdo de 18:3.

Esses resultados de associação são condizentes com os encontrados em outras populações derivadas de cruzamentos que envolvam os mesmos alelos de A29, como na $\mathrm{RC}_{1} \mathrm{~F}_{2}$ derivada de SS97-6946 x (SS97-6946 x IA3017) de Bilyeu et al. (2006), e alelos diferentes de A29, como em $F_{2}$ de Williams 82 x 2721 de Bilyeu et al. (2005). Dessa forma, os genes FAD $3 A$, $F A D 3 B$ e $F A D 3 C$ contribuem para o conteúdo total de 18:3 em sementes de soja. Além disso, as mutações no gene $F A D 3 A$ provocam maior efeito na variação do conteúdo de 18:3 que as mutações observadas nos outros dois locos (Bilyeu et al., 2003, 2005, 2006, 2011).

Não foi detectado efeito de "background" genético para os genes $F A D 3 A, F A D 3 B$ e FAD $3 C$.

A partir das análises apresentadas, é possível verificar que o conteúdo de 18:3 de variedades adaptadas às regiões brasileiras pode ser manipulado de acordo com a combinação dos diferentes alelos de $F A D 3 A, F A D 3 B$ e $F A D 3 C$, oriundos do genótipo A29. Com a validação da associação dos marcadores moleculares será possível empregar a seleção assistida por marcadores, a fim de introduzir alelos para baixo conteúdo de 18:3.

Tabela 7. Coeficientes de regressão dos efeitos genotípicos dos marcadores $F A D 3 B$ e $F A D 3 C$ sobre o conteúdo de ácido linolênico nas gerações F2 e F2:3, tendo-se considerado os genótipos quanto ao marcador $F A D 3 A$.

\begin{tabular}{|c|c|c|c|c|}
\hline \multirow[t]{2}{*}{ Efeito genotípico $^{(1)}$} & \multicolumn{2}{|c|}{ A } & \multicolumn{2}{|c|}{ aa } \\
\hline & $\mathrm{F}_{2}$ & $\mathrm{~F}_{2: 3}$ & $\mathrm{~F}_{2}$ & $\mathrm{~F}_{2: 3}$ \\
\hline$F A D 3 B$ (a) & $-1,99 * *$ & $-1,46^{* *}$ & $0,72 *$ & $-0,93 * *$ \\
\hline$F A D 3 B(\mathrm{~d})$ & 0,63 & 0,22 & $-0,62$ & 0,02 \\
\hline$F A D 3 C$ (a) & $-1,49 * *$ & $-2,56 * *$ & $-0,18 * *$ & $-1,57 * *$ \\
\hline$F A D 3 C(\mathrm{~d})$ & 0,11 & $0,57 *$ & $-0,27$ & 0,19 \\
\hline Epistasia (aa) & 1,52 & $-0,47$ & $-1,72$ & $-0,79$ \\
\hline Epistasia (ad) & $-0,18$ & 0,89 & 0,69 & 0,57 \\
\hline Epistasia (da) & $-0,64$ & 0,44 & 0,68 & 0,86 \\
\hline Epistasia (dd) & 0,09 & $-0,53$ & $-0,28$ & $-0,50$ \\
\hline $\mathrm{R}_{2}$ ajustado & 33,46 & 21,11 & 23,58 & 61,38 \\
\hline
\end{tabular}

(1)a e d correspondem aos efeitos aditivos e de dominância, respectivamente; aa, ad, da e dd correspondem aos efeitos de epistasia: aditivo-aditivo, aditivo-dominante, dominante-aditivo e dominante-dominante, respectivamente. $*$ e $* *$ Significativo a 5 e $1 \%$ de probabilidade, respectivamente.

\section{Conclusões}

1. Os genes $F A D 3 A$, FAD3B e $F A D 3 C$ apresentam, predominantemente, ação gênica aditiva no controle do conteúdo de 18:3, em sementes de soja.

2. As substituições alélicas no loco FAD $3 A$ proporcionam maiores variações no conteúdo de 18:3 que as substituições nos locos $F A D 3 B$ e $F A D 3 C$.

3. Os SNPs para os genes FAD3A, FAD3B e FAD3C podem ser utilizados em programas de seleção assistida para baixo conteúdo de ácido linolênico em soja.

\section{Agradecimentos}

Ao Conselho Nacional de Desenvolvimento Científico e Tecnológico (CNPq), à Coordenação de Aperfeiçoamento de Pessoal de Nível Superior (Capes) e à Fundação de Amparo à Pesquisa do Estado de Minas Gerais (Fapemig), pelo apoio financeiro.

\section{Referências}

ANAI, T.; YAMADA, T.; KINOSHITA, T.; RAHMAN, S.M.; TAKAGI, Y. Identification of corresponding genes for three low- $\alpha$-linolenic acid mutants and elucidation of their contribution to fatty acid biosynthesis in soybean seed. Plant Science, v.168, p.1615-1623, 2005. DOI: 10.1016/j.plantsci.2005.02.016.

BACHLAVA, E.; CARDINAL, A.J. Correlation between temperature and oleic acid seed content in three segregating soybean populations. Crop Science, v.49, p.1328-1335, 2009. DOI: 10.2135/cropsci2008.11.0660.

BACHLAVA, E.; DEWEY, R.E.; BURTON, J.W.; CARDINAL, A.J. Mapping and comparison of quantitative trait loci for oleic acid seed content in two segregating soybean populations. Crop Science, v.49, p.433-442, 2009. DOI: 10.2135/cropsci2008.06.0324.

BAUD, S.; LEPINIEC, L. Physiological and developmental regulation of seed oil production. Progress in Lipid Research, v.49, p.235-249, 2010. DOI: 10.1016/j.plipres.2010.01.001.

BILYEU, K.D.; GILLMAN, J.D.; LEROY, A.R. Novel FAD3 mutant allele combinations produce soybeans containing $1 \%$ linolenic acid in the seed oil. Crop Science, v.51, p.259-264, 2011. DOI: 10.2135/cropsci2010.01.0044.

BILYEU, K.D.; PALAVALLI, L.; SLEPER, D.A.; BEUSELINCK, P.R. Molecular genetic resources for development of $1 \%$ linolenic acid soybeans. Crop Science, v.46, p.1913-1918, 2006. DOI: 10.2135/cropsci2005.11-0426.

BILYEU, K.D.; PALAVALLI, L.; SLEPER, D.A.; BEUSELINCK, P.R. Mutations in soybean microsomal omega-3 fatty acid desaturase genes reduce linolenic acid concentration in soybean seeds. Crop Science, v.45, p.1830-1836, 2005. DOI: 10.2135/ cropsci2004.0632. 
BILYEU, K.D.; PALAVALLI, L.; SLEPER, D.A.; BEUSELINCK, P.R. Three microsomal omega-3 fatty-acid desaturase genes contribute to soybean linolenic acid levels. Crop Science, v.43, p.1833-1838, 2003. DOI: 10.2135/cropsci2003.1833.

CARDINAL, A.J.; BURTON, J.W.; CAMACHO-ROGER, A.M.; WHETTEN, R.; CHAPPELL, A.S.; BILYEU, K.D.; AUCLAIR, J.; DEW, R.E. Molecular analysis of GmFAD3A in two soybean populations segregating for the fan, fapl, and fap loci. Crop Science, v.51, p.2104-2112, 2011. DOI: 10.2135/ cropsci2010.08.0500.

CARRERA, C.; MARTINEZ, M.J.; DARDANELLI, J.; BALZARINI, M. Environmental variation and correlation of seed components in nontransgenic soybeans: protein, oil, unsaturated fatty acids, tocopherols, and isoflavones. Crop Science, v.51, p.800-809, 2011. DOI: 10.2135/cropsci2010.06.0314.

CHAPPELL, A.S.; BILYEU, K.D. The low linolenic acid soybean line PI 361088b contains a novel GmFAD3A mutation. Crop Science, v.47, p.1705-1710, 2007. DOI: 10.2135/ cropsci2006.12.0783.

CRUZ, C.D. Programa GENES: estatística experimental e matrizes. Viçosa: UFV, 2006. 285p.

CRUZ, C.D.; SCHUSTER, I. GQMOL: aplicativo computacional para análise de dados moleculares e de suas associações com caracteres quantitativos. 2012. Disponível em: <http://www.ufv.br/ dbg/gqmol/gqmol.htm>. Acesso em: 10 ago. 2012.

DOYLE, J.J.; DOYLE, J.L. A rapid total DNA preparation procedure for fresh plant tissue. Focus, v.12, p.13-15, 1990.

FARHOOSH, R.; EINAFSHAR, S.; SHARAYEI, P. The effect of commercial refining steps on the rancidity measures of soybean and canola oils. Food Chemistry, v.115, p.933-938, 2009. DOI: 10.1016/j.foodchem.2009.01.035.

FEHR, W.R. Breeding for modified fatty acid composition in soybean. Crop Science, v.47, p.72-87, 2007. DOI: 10.2135/ cropsci2007.04.0004IPBS.

GERDE, J.; HARDY, C.; FEHR, W.; WHITE, P.J. Frying performance of no-trans, low-linolenic acid soybean oils. Journal of the American Oil Chemists' Society, v.84, p.557-563, 2007. DOI: 10.1007/s11746-007-1066-0.

JHAM, G.N.; TELES, F.F.F.; CAMPOS, L.G. Use of aqueous HCl/ $\mathrm{MeOH}$ as esterification reagent for analysis of fatty acids derived from soybean lipids. Journal of the American Oil Chemists' Society, v.59, p.132-133, 1982.

KNOTHE, G. Some aspects of biodiesel oxidative stability. Fuel Processing Technology, v.88, p.669-677, 2007. DOI: 10.1016/j. fuproc.2007.01.005.
MAHMOUD, A.A.; NATARAJAN, S.S.; BENNETT, J.O.; MAWHINNEY, T.P.; WIEBOLD, W.J.; KRISHNAN, H.B. Effect of six decades of selective breeding on soybean protein composition and quality: a biochemical and molecular analysis. Journal of Agricultural and Food Chemistry, v.54, p.3916-3922, 2006. DOI: $10.1021 /$ jf060391m.

OLIVA, M.L.; SHANNON, J.G.; SLEPER, D.A.; ELLERSIECK, M.R.; CARDINAL, A.J.; PARIS, R.L.; LEE, J.D. Stability of fatty acid profile in soybean genotypes with modified seed oil composition. Crop Science, v.46, p.2069-2075, 2006. DOI: 10.2135/cropsci2005.12.0474.

PRIMOMO, V.S.; FALK, D.E.; ABLETT, G.R.; TANNER, J.W.; RAJCAN, I. Inheritance and interaction of low palmitic and low linolenic soybean. Crop Science, v.42, p.31-36, 2002. DOI: 10.2135/cropsci2002.0031.

RAMOS, M.J.; FERNÁNDEZ, C.M.; CASAS, A.; RODRÍGUEZ, L.; PÉREZ, A. Influence of fatty acid composition of raw materials on biodiesel properties. Bioresource Technology, v.100, p.261-268, 2009. DOI: 10.1016/j.biortech.2008.06.039.

REINPRECHT, Y.; LUK-LABEY, S.-Y.; LARSEN, J.; POYSA, V.W.; YU, K.; RAJCAN, I.; ABLETT, G.R.; PAULS, K.P. Molecular basis of the low linolenic acid trait in soybean EMS mutant line RG10. Plant Breeding, v.128, p.253-258, 2009. DOI: 10.1111/j.1439-0523.2008.01571.x.

SANTOS, E.M.; PIOVESAN, N.D.; BARROS, E.G.; MOREIRA, M.A. Low linolenic soybeans for biodiesel: characteristics, performance and advantages. Fuel, v.104, p.861-864, 2013. DOI: 10.1016/j.fuel.2012.06.014.

WANG, X.; JIANG, G.-L.; GREEN, M.; SCOTT, R.A.; HYTEN, D.L.; CREGAN, P.B. Quantitative trait locus analysis of saturated fatty acids in a population of recombinant inbred lines of soybean. Molecular Breeding, v.30, p.1163-1179, 2012. DOI: 10.1007/ s11032-012-9704-0.

WILSON, R.F. Seed composition. In: BOERMA, H.R.; SPECHT, J.E. (Ed.). Soybeans: improvement, production, and uses. $3^{\text {rd }}$ ed. Madison: ASA/CSSA/SSSA, 2004. p.521-677.

XIE, D.; HAN, Y.; ZENG, Y.; CHANG, W.; TENG, W.; LI, W. SSR- and SNP-related QTL underlying linolenic acid and other fatty acid contents in soybean seeds across multiple environments. Molecular Breeding, v.30, p.169-179, 2012. DOI: 10.1007/ s11032-011-9607-5.

XU, Y.; CROUCH, J.H. Marker-assisted selection in plant breeding: from publications to practice. Crop Science, v.48, p.391-407, 2008. DOI: 10.2135/cropsci2007.04.0191.

Recebido em 16 de agosto de 2012 e aprovado em 8 de fevereiro de 2013 